\title{
Management of digital records for knowledge preservation in academic institutions for a sustainable development in education sector
}

\author{
Justice Chinonso Ujoumunna*, Emmanuel Chibueze Agbawudikeizu**
}

\author{
Received: 2021-09-11 \\ Accepted: 2021-10-17 \\ DOI: http://doi.org/10.46489/lbsh.2021-1-3-1
}

\begin{abstract}
Building and managing digital collections or information resources for knowledge perseveration in academic institutions, especially tertiary institutions, has increasingly become more needful than ever before as many believe it remains the way out for sustainable academic teaching and learning in the 21 st century. This belief stems from the fact that the 21 st-century teaching and learning activities, as well as research, has already moved to a digital base, especially as the new normal, having witnessed the sudden emergence of coronavirus 19 with physical restrictions to buildings where physical collections are housed such as the library and other information centres. From the data collection stage to the research data analysis to the publication stage, knowledge preservation has fully embraced digital processes where Google forms, Survey Hearts and Monkeys are now used for building data. Questionnaires, interviews, and so many other instruments are now done through digital processes and mediums, thereby building the collection of knowledge in the digital format. The issue may not really be the processes of building the collections in the digital format, however, but the management of these digital collections in the digital format to preserve the knowledge for posterity via different databases and digital preservation processes. Therefore, this opinion paper is designed to explore different kinds of literature on this subject area of digital collections management to close the gap in this area of digital collections for a 21st-century academic institution and to proffer some recommendations with a special interest in institutional repositories moving fully into automated version. Therefore, the opinion of this paper is to review relevant literature to argue whether digital collections in academic institutions is the way out for sustainable development in the knowledge management aspect.
\end{abstract}

Keywords: building, management, digital collections, knowledge preservation and academic institutions.

\footnotetext{
* Justice Chinonso Ujoumunna, Research Scholar, University of Liverpool, Brownlow Hill, L69 7ZX Liverpool, United Kingdom, e-mail: j.c.ujoumunna@liverpool.ac.uk, ORCID: https://orcid.org/0000-0001-5274-662X

** Emmanuel Chibueze Agbawudikeizu, Teaching Assistant, Department of Library and Information Science, Federal Polytechnic, P.M.B. 021, Aguata Anambra State, Nigeria, e-mail: chibuezem@gmail.com, ORCID: https://orcid.org/00000001-7205-6132
} 


\section{INTRODUCTION}

There are a whole lot of collections dilapidating in academic institutions today (Seal, 2012). Some have argued that the problem is lack of care. Others have maintained a lack of expertise. Recently, many have linked it to the restrictions of the new normal. However, despite either lack of care or expertise, the truth remains that there is a general belief that preservation of knowledge in academic institutions is at a challenging state in general and in Global South Countries in particular (Balogun, 2021). This paper has identified the building and management of digital collections in academic institutions as a way out of this critical situation and sustainable development goals. Therefore, the effort has been made to review the literature and other scholarly views on the various ways of building digital collections before contemplating the management processes using institutional repositories as a case study for knowledge preservation and for sustainable development.

\section{RESULTS}

\section{Building Digital Collections in Academic Institutions}

Digital collections come in different formats like PDF, CDRom, Microfilm, WPS, Audio-visuals, and so many other digital files. Again, digital collections are generated through different publications like textbooks, manuals, articles, conference papers, long essays, dissertations, thesis, lecture notes and manuals, as well as other academic outputs for teaching, learning and research activities (Watkins, 2015). All materials in the library are called library collections. These collections could be of two different types, which are digital or manual materials. In building institutional repositories, Sutradhar (2006) demonstrates how to create different communities in IRs by using various types of collections in open source software, namely DSpace for digital collections. On the same preservation of digital collections, Green (2009), through a descriptive review, pinpoints the factors that lead to the digital library of the British Council by identifying the goals, priorities and mediums to provide access to digital collections.

The digital materials are all collections in the electronic format (Williams, 2014). That is to say that they are either produced or stored in a computer device. The other is the physical, traditional or non-digital materials like the physical book.

To build digital collections, efforts are made to fully automate the library and to ensure continuous acquisitions of digital version of all materials in the library (Brox, 2016). It will also include the retrospective conversion of already existing library materials in the library to digital format. Building digital collections require concerted efforts to ensure all collections received in the library are in digital format. It is only at such attainment that knowledge management in academic institutions is sustainable (Sapta, 2021).

Because this paper is focused on institutional repository, the department in charge of students' reports like long essays, dissertations and thesis or other research findings and field results should be deliberately processed and organized in digital format and same should be made visible and available in the institutional database for public access. Through this, digital collections are preserved for posterity. Not only building up but also after building up these digital collections, the management of these collections is paramount.

\section{Management of Digital Collections in Academic Institutions}

Management of digital collections in academic institutions requires professional skills and ethical standards of preservation practices in the management approach. What does this mean; the issue of building up these digital collections is not only the major effort needed but its sustainability.

Management is the process of keeping something safe and fresh. It entails safekeeping, maintenance, and proper arrangement for both easy and future use. The issue of managing digital collections in academic institutions is to ensure the preservation of knowledge in the digital format where users can access the institutional repository from any location. Then, what is maintained? Remember that we are interested in digital materials in this review. Therefore, the computer devices or host of these digital collections requires adequate care from time to time. In maintaining digital collections in institutional repositories, Xia and 
$\mathrm{Li}$ (2006) give a group of factors that could help maintain and preserve digital collections in IRs, such as Depositors and Availability. This means that research outputs must be deposited and made available.

Managing digital collections also involves the considerations of the records life cycle, which includes the creation period to disposal time where data curation policies have played roles in such management processes. For proper management, Opperman (2009) also gives important considerations such as open access, full-text, operational style and content compositions.

\section{Institutional Repositories}

Institutional repositories are indigenous knowledge produced out of research inputs and outputs by members of the university community. They are built up in different works such as research data and results, long essays and dissertations, thesis. Others are lecture manuals and special lecture material delivered within the university. According to Saini (2018), he maintains that "an institutional repository is an online archive of the intellectual output created by the faculty and researchers of an institution to enhance the visibility and promote free access of the research at a single interface." These outputs are either in different subject areas or in a particular discipline, usually depending on the university's disciplines. Sharing an opinion about the versions of the institutional repository, Ware (2004) says that institutional repositories are a "web-based database of scholarly materials recorded for long-term preservation using OAI-compliant software to collect, store, preserve, and disseminate of the scholarly materials in digital form among the academic communities."

Still on the building and management of digital collections for knowledge preservation, Crow (2002) sees Institutional repository as "digital collections capturing and preserving the intellectual output of a single or multi-university community to provide a compelling response to two strategic issues facing academic institutions." These two strategic issues could mean the teaching and research activities of the faculty members of the academic institution.

\section{Key Components for Building Institutional repositories for Digital Preservation}

Rieh et al. (2007) explore some major components before setting up an institutional repository for knowledge preservation in academic institutions. They are

- leadership;

- funding;

- content;

- contributors;

- systems.

Based on these four key components, this paper is focused on reviewing and exploring the building and management of digital collections for knowledge preservation in academic institutions with a special interest in institutional repositories where this knowledge is housed.

However, the first component is leadership. On this aspect, before building institutional repositories, one of the academic institutions needs to know who and how the management would be designed to preserve such information materials containing the faculty members' research output. It is a general belief that any project without maintenance is subject to ridicule hence, the effort to consider how and who manages the database of such knowledge. Again, so many institutions have wrongly placed the management of institutional repositories in the school's computer centre or ICT unit rather than the library. Therefore, this paper aims to let the scholars know that from every indication, the library remains the house of knowledge and the appropriate place to build and manage any collection, be it physical material or digital collection.

The second component is funding. The library is a growing organism and continues to grow with adequate funding by either doing the library's quarterly or annual budget allocation. This helps to acquire and maintain library collections. As part of the library, the institutional repository can only be maintained through adequate funding that keeps both the hardware and software devices in normal functioning status. Only with funding can the knowledge will continue to grow. Most institutional repositories go further to fund some research to close the gap and provide 
literature on trending areas of study to increase visibility.

The third is the content, where questions like what kind of materials are to be hosted in the database. What usually come to mind are scholarly publications, such as research findings and results of the faculty members in the university? Of course, the content shows the quality of research done in any academic institution. Some institutional repositories are designed to host materials on specific areas, while others host digital collections on all disciplines the institution supports her teaching, learning and research activities. To support the above view, Doctor and Ramachandran (2008) emphasise the need for intellectual capital and its sharing impacts among research communities of the academic institution.

The fourth is the contributors that stress whose work is to be deposited in the database for preservation, visibility, and availability. The contributors are usually the academic faculty of the institutions where such a repository is domiciled. Others are scholars both visiting and on a research basis whose works have been admitted to the academic board of the institution.

The last component to be considered is the system. The system here means the operational system, system architecture, organisational structure and mode of accessibility of the content. The choice of the system hardware and software chosen affects the build-ups and management of the institutional repositories automatically.

\section{References}

Balogun, T., \& Kalusopa, T. (2021). A framework for digital preservation of Indigenous knowledge system (IKS) in repositories in South Africa. Records Management Journal, 31(2), 176196. https://doi.org/10.1108/RMJ-12-2020$\underline{0042}$

Brox, M., Gersnoviez, A., Bujalance, I., Quiles, F. J., Ortiz, M. A., \& Brox, P. (2016). DigitalLib: A VHDL library of basic blocks to automate the design of advanced digital systems. 2016 Technologies Applied to Electronics Teaching (TAEE), 17. https://doi.org/10.1109/TAEE.2016.75282 $\underline{47}$

\section{RECOMMENDATIONS}

Building up and managing digital collections for knowledge preservation in academic institutions requires a concerted effort of professionals in any institution. The effort entails establishing policies for effective and sustainable management of the institutional repository and considerations of the key components that should be looked into before building such a database. Having said this, the recommends that

1. Institutions must ensure that Professional librarians set up iRs as the only way to sustain knowledge in academic institutions.

2. Such Digital Collections of knowledge should be domiciled in the library and not ICT or the Computer centre of institutions for Sustainability.

3. There should be adequate funding for the preservation of digital collections throughout the year for Sustainability.

\section{CONCLUSION}

This paper has reviewed different scholarly views of building and management of digital collections which is usually housed as institutional repositories in academic institutions. The discussed the idea of building digital collections, its management, key components and recommended some important considerations going forward in a conceptual meaning.

Crow, R. (2002). The case for institutional repositories: a SPARC position paper. www.arl.org/spare/IR/ir.html

Doctor, G. \& Ramchandram, S. (2008). Considerations for implementing an institutional repository at a business schools in India. International Journal of Informational Management, $28 \quad$ (2008), 346-354. bttp:// doi.org/10.1016/j.ijiinfmgt.2007.12.001

Green, S. (2009). The digital library programme at the British Library: goal and priorities. Interlending \& Document Supply, 37 (3), 136-

139. http://www.emerldinsight.com/insight/V eiwContentServlet?contentType $=$ Article\&Filen ame $=$ Published/EmeraldFullTextArticle/Articl es/122070304.html 
Opperman, B., Carr, L., \& Swan, A. (2009). Institutions: their repositories and the web. Serials Review, 34 (1), 240-254.

Rieh, S. Y., Jean, B. S., Yakel, E ., \& Kim, J. (2008). Perceptions and experiences of staff in the planning and implementation of institutional repository. Library Trends, 52 (2), 168-190.

Saini, O. P. (2018). The emergence of institutional repositories: a conceptual understanding of key issues through review of literature. Library Philosophy and Practices. Fall 2018. 1774p

Sapta, I. K. S., Sudja, I. N., Landra, I. N., \& Rustiarini, N. W. (2021). Sustainability Performance of Organization: Mediating Role of Knowledge Management. Economies, 9(3), 97. https://doi.org/10.3390/economies 903009 7

Seal, R. A. (2012). Special Collections in Academic Libraries: Introduction. Journal of Library Administration, 52(3-4), 231232. https://doi.org/10.1080/01930826.2012.6 $\underline{92934}$

Sutradhar, B. (2006). Design and development of an institutional repository at the Indian Institute of Technology kharagpur.
Program: Electronic Library and Information Systems, 40

(3), $244-$

255. http://www.emerldinsight.com/insight/V eiwContentServlet? contentType $=$ Article\&Filen ame $=$ Published/EmeraldFullTextArticle/Articl es/122070304.html

Ware, V and Saini, O. P. (2004). Institutional repository in academia of Northern India: concept creation and challenge. Saarbrucken, Germany: Lambert. 191p.

Watkins, R. D., Sellen, A., \& Lindley, S. E. (2015). Digital Collections and Digital Collecting Practices. Proceedings of the 33rd Annual ACM Conference on Human Factors in Computing Systems, 34233432. https://doi.org/10.1145/2702123.27023 $\underline{80}$

Williams, G. (2014). Book Review: Developing and Managing Electronic Collections: The Essentials. Library Resources \& Technical Services, 58(3), 215. https://doi.org/10.5860/lrts.58n3.209g

$\mathrm{Xia}, \mathrm{J}$. \& Li, S. (2006). Factors to assess self-archiving in institutional repositories. Serials Review, $\quad 33$ (2), 77-80. http://doi.org/10.1016./jserrv.2006.002 